\title{
Towards a coherent global framework for health financing: recommendations and recent developments
}

\author{
TRYGVE OTTERSEN* \\ Oslo Group on Global Health Policy, Department of Community Medicine and Global Health and Centre for Global \\ Health, University of Oslo, Oslo, Norway \\ Department of Global Public Health and Primary Care, University of Bergen, Bergen, Norway \\ Department of International Public Health, Norwegian Institute of Public Health, Oslo, Norway \\ RIKU ELOVAINIO \\ World Health Organization, Egypt Country Office, Cairo, Egypt \\ DAVID B. EVANS \\ Health Systems Research and Dynamic Modelling Group, Swiss Tropical and Public Health Institute, \\ Switzerland \\ University of Basel, Basel, Switzerland \\ DAVID MCCOY \\ Centre for Primary Care and Public Health, Queen Mary University of London, London, UK \\ DI MCINTYRE \\ Health Economics Unit, School of Public Health and Family Medicine, Faculty of Health Sciences, University of Cape \\ Town, Cape Town, South Africa \\ FILIP MEHEUS \\ Health Economics Unit, School of Public Health and Family Medicine, Faculty of Health Sciences, University of Cape \\ Town, Cape Town, South Africa \\ SUERIE MOON \\ Department of Global Health and Population, Harvard T.H. Chan School of Public Health, Harvard University, \\ Boston, MA, USA \\ GORIK OOMS \\ Institute of Public Health, Heidelberg University, Heidelberg, Germany \\ JOHN-ARNE RØTTINGEN \\ Department of Health Management and Health Economics, University of Oslo, Oslo, Norway \\ Harvard T.H. Chan School of Public Health, Harvard University, Boston, MA, USA \\ Infectious Disease Control and Environmental Health, Norwegian Institute of Public Health, Oslo, Norway
}

\begin{abstract}
The articles in this special issue have demonstrated how unprecedented transitions have come with both challenges and opportunities for health financing. Against the background of these challenges and opportunities, the Working Group on Health Financing at the Chatham House Centre on Global Health Security laid out, in 2014, a set of policy responses encapsulated in 20 recommendations
\end{abstract}

"Correspondence to: Trygve Ottersen, Department of Community Medicine and Global Health, Institute of Health and Society, PO Box 1130 Blindern, 0318 Oslo, Norway. Email: trygve.ottersen@medisin.uio.no 
for how to make progress towards a coherent global framework for health financing. These recommendations pertain to domestic financing of national health systems, global public goods for health, external financing for national health systems and the cross-cutting issues of accountability and agreement on a new global framework. Since the Working Group concluded its work, multiple events have reinforced the group's recommendations. Among these are the agreement on the Addis Ababa Action Agenda, the adoption of the Sustainable Development Goals, the outbreak of Ebola in West Africa and the release of the Panama Papers. These events also represent new stepping stones towards a new global framework.

\section{Background and recommendations}

Financing is at the centre of efforts to improve health and health systems. It is only when resources are adequately, efficiently and equitably mobilised, pooled and spent that all people can enjoy sustained progress towards universal health coverage (UHC) and the full benefits of global public goods for health (GPGHs).

The articles in this special issue have demonstrated how unprecedented transitions and new and persisting challenges shared by all countries put such progress at risk, and do so particularly for low- and middle-income countries. These transitions include profound changes in the global economy, changes in health and risk factors for disease, and transformations of the institutional landscape of global health. Despite important advances, persisting challenges include poor health outcomes, poor access to health services and financial risks to patients stemming from out-of-pocket health service payments. These are compounded by profound inequalities both between and within countries and by uneven distribution of recent improvements.

Health financing is central to meeting these grand challenges. But to do so effectively, shortcomings in today's approach to health financing must be addressed. As shown in Table 1, we believe the current approach must be revised with respect to the domestic financing of national health systems, the joint financing of GPGHs, and the external financing of national health systems where domestic capacity is inadequate.

Recent and ongoing transitions also come with unprecedented opportunities to improve health financing. Economic growth in many countries expands the fiscal space for domestic spending on health. Projections up to 2035 forecast real gross domestic product (GDP)-growth per year at $4-5,4.3$ and $4.2 \%$ for low-, lower-middle and upper-middle-income countries, respectively (Jamison et al., 2013). The proliferation of global health institutions provides an opportunity to test a variety of financing arrangements and draw lessons from natural experiments. At the national level, governments demonstrate increasing 
Table 1. Shortcomings in today's approach to health financing

\begin{tabular}{lll}
\hline \hline $\begin{array}{l}\text { Domestic financing of } \\
\text { national health systems }\end{array}$ & $\begin{array}{l}\text { Joint financing of global } \\
\text { public goods for health }\end{array}$ & $\begin{array}{l}\text { External financing for } \\
\text { national health systems }\end{array}$ \\
\hline $\begin{array}{ll}\text { Insufficient total funds } \\
\text { Over-reliance on out-of-pocket payments } \\
\begin{array}{l}\text { Inadequate mechanisms to raise public finance } \\
\text { through effective tax and revenue systems }\end{array}\end{array}$ & $\begin{array}{l}\text { Insufficient total funds } \\
\text { Inadequate focus among } \\
\text { countries } \\
\text { Inadequate institutions and } \\
\text { Rudimentary mechanisms for mandatory } \\
\text { prepayment with pooling of funds }\end{array}$ & $\begin{array}{l}\text { Insufficient total funds } \\
\text { Unsettled contribution norms } \\
\text { action }\end{array}$ \\
$\begin{array}{c}\text { Problematic priorities and inefficient } \\
\text { health spending }\end{array}$ & & $\begin{array}{l}\text { Volatility and uncertainty } \\
\text { Inadequate accountability }\end{array}$ \\
\hline \hline
\end{tabular}

added to the list presented in the original report.

willingness to invest in health and explore new financial mechanisms in the context of UHC.

Against the background of these challenges and opportunities, the Working Group on Health Financing at the Chatham House Centre on Global Health Security laid out a set of policy responses encapsulated in 20 recommendations for how to make progress towards a coherent global framework for health financing (Panel 1) (Røttingen et al., 2014). While the recommendations speak to different areas of health financing, the Working Group emphasised how these areas closely interact and how a comprehensive view is needed to attain coherence. The recommendations also shared a common basis in justice, solidarity and human rights.

\section{Panel 1: recommendations}

The recommendations offered by the Working Group fall into four categories. Recommendations in the first category describe what every government should do to strengthen the domestic financing of national health systems. These recommendations cover resource mobilisation, pooling and use, and include key targets for health expenditure. The recommendations in the second category emphasise the additional responsibility governments have to help finance and provide GPGHs, describe how this can be done, and point to how other actors can facilitate the process. Recommendations in the third category describe how governments and other donors can provide more and smarter external financing for health and offer a key target for governments' contributions. Recommendations in the final category cut across the others. These recommendations pertain to how accountability can be strengthened and how agreement can be sought to make progress towards a coherent global framework. 


\section{Domestic financing of national bealth systems}

To strengthen domestic financing of national health systems, the Working Group concluded that

1. Every government should meet its primary responsibility for securing the health of its own people. This involves a responsibility to oversee domestic financing for health and ensure that it is sufficient, efficient, equitable and sustainable.

2. Every government should commit to spend at least $5 \%$ of GDP on health and move progressively towards this target, and every government should ensure government health expenditures (GHE) per capita of at least $\$ 86^{1}$ whenever possible. Most middle-income countries should be able to reach both targets without external support.

3. Every government should ensure that catastrophic and impoverishing outof-pocket payments (OOPPs) are minimised. Specifically, governments should commit to the targets of OOPPs representing $<20 \%$ of total health expenditures (THE) and no OOPPs for priority services or for the poor.

4. Every government should improve revenue generation and achieve reduction of OOPPs through effective, equitable and sustainable ways of increasing mandatory prepaid pooled funds for health services. Individual contributions to the pool(s) should primarily be based on capacity to pay and be progressive with respect to income.

5. Every government should consider improved and innovative taxation as a means to raise funds for health. Promising policies include the introduction or strengthening of excise taxes related to tobacco, alcohol, sugar and carbon emissions, and these should be combined with measures to increase tax compliance, reduce illicit flows and curb tax competition among countries. Other sources of government revenue, particularly in countries rich in natural resources, should also be explored.

6. Every government should ensure that mandatory prepaid pooled funds are used with the aim of making progress towards UHC - that is, affordable access for everyone. Specifically, every government should seek to ensure a universal health system with full population coverage of comprehensive primary health care, highpriority specialized care and public health measures, and should not prioritise expanding coverage of a more comprehensive set of services for only some privileged groups in society.

7. Every government, in collaboration with civil society, should formalize systematic and transparent processes for priority-setting and for defining a comprehensive set of entitlements based on clear, well-founded criteria. Potential criteria include those related to cost-effectiveness, severity and financial risk protection. The processes can build on the methods of health technology assessment and multicriteria decision analysis, which can help translate evidence and explicit values into policy decisions.

1 In the original report, this estimate was in 2012 \$US terms. An update to 2015 \$US terms based on inflation and exchange rates generated the exact same figure, partly due to negative inflation rates in some countries (McIntyre et al., 2017). 
8. Every government and other actor involved in the financing or provision of health care must continuously strive to improve efficiency. In particular, this will require action on corruption and strategic purchasing, with continuous assessment and active management of which services are purchased and what providers and payment mechanisms are used.

\section{Joint financing of global public goods}

To strengthen joint financing of GPGHs, the Working Group concluded that

9. Every government should meet its key responsibility for the co-financing of GPGHs and take the necessary steps to correct the current undersupply of such goods. Among key GPGHs are health information and surveillance systems, and research and development for new technologies that specifically meet the needs of the poor. Public funding for the latter purpose should be at least doubled compared with the current level.

10. Every government should increase its support for new and existing institutions charged with the financing or provision of GPGHs. In particular, the World Health Organization's capacity to provide GPGHs should be enhanced and adequate funds provided on a sustainable basis for that purpose.

11. Every government, international organisation, corporation and other key actor should promote a global environment that enables all countries to pursue government-revenue policies that can sufficiently finance their social sectors, including health, education and welfare. This requires action on illicit financial flows, tax havens, harmful tax competition and overexploitation of natural resources.

\section{External financing for national health systems}

To strengthen external financing for national health systems, the Working Group concluded that

12. Every country with sufficient capacity should contribute with external financing for health. Determination of capacity should partly depend on GDP per capita. Net contributing countries should include all high-income countries and most upper-middle-income countries and not only member countries of the Organisation for Economic Co-operation and Development's Development Assistance Committee (OECD-DAC).

13. High-income countries should commit to provide external financing for health equivalent to at least $0.15 \%$ of GDP. Most upper-middle-income countries should commit to progress towards the same contribution rate.

14. Every provider of external financing for health, including contributing countries and international organisations, should establish clear, well-founded and publicly available criteria to guide the allocation of resources. These should be the outcome of broad, deliberative processes with input from key stakeholders, including civil society in contributing and recipient countries. 
15. Every provider of external financing for health should align its support with recipient-country government priorities to the greatest extent possible. This calls for strong adherence to the Paris Declaration on Aid Effectiveness and the Accra Agenda for Action. In particular, providers of external financing for health should encourage and comply with national plans and strategies, improve transparency and monitoring of disbursements and results, and help to build domestic governance and institutional capacity.

16. All providers of external financing for health should strive to strengthen coordination among themselves and with each recipient country, in order to improve efficiency as well as equity. In particular, they should encourage and comply with country-led division of labour, harmonise procedures, increase the use of joint and shared arrangements, and improve information sharing.

17. Every government should actively assess the existing mechanisms for pooling of external funds for health - including the Global Fund to Fight AIDS, Tuberculosis and Malaria; Gavi, the Vaccine Alliance (Gavi); and the World Bank's health trust funds - and consider the feasibility of broader mandates, mergers and increased global pooling with the aim of improving efficiency and equity.

\section{Accountability and agreement}

Strong accountability mechanisms and global agreement on responsibilities, targets and strategies will facilitate the implementation of the needed policy responses and a coherent global framework. The Working Group concluded that

18. Every government and other actor involved in domestic or external financing or in the provision of health services should seek to strengthen accountability at global, national and local levels. This should be done by improving transparency about decisions, resource use and results, by improving monitoring and data collection and by ensuring critical evaluation of information with effective feedback into policy making. Accountability should also be strengthened through active monitoring by civil society and by ensuring the broad participation of stakeholders throughout the policy process.

19. Every government and other key actor should seek to ensure that health and UHC are central goals and yardsticks in the post-2015 development agenda. These actors should also seek to ensure that the responsibilities, targets and strategies of a coherent global framework for health financing are integrated to the fullest extent possible. Moreover, the agenda should make clear that health is important both for its own sake and for the sake of other goals, including poverty eradication, economic growth, better education and sustainability.

20. All stakeholders should enter into a process of seeking global agreement on key responsibilities, targets and strategies for health financing - including on the mechanisms for monitoring and enforcement - in order to expedite the implementation of a coherent global financing framework. In the short term, consultation on the post-2015 development agenda is one useful arena for 
building consensus, and the agenda itself can be a valuable commitment device. In the longer term, a more specific process should be devised in one or more relevant forums, such as the UN General Assembly, the World Health Assembly, World Bank/International Monetary Fund, or a high-level standalone meeting.

\section{Recent developments and the way forward}

Since the Working Group concluded its work, multiple events have reinforced the group's recommendations. The Third International Conference on Financing for Development took place in July 2015 and resulted in the Addis Ababa Action Agenda (United Nations (UN), 2015a). Two months later the 2030 Agenda for Sustainable Development, with the Sustainable Development Goals (SDGs), was adopted in New York (United Nations (UN), 2015b). Both endorsed UHC. The Addis Ababa Action Agenda committed governments to a new social compact, to provide fiscally sustainable and nationally appropriate social protection systems and measures for all, and to achieve UHC. In the 2030 Agenda for Sustainable Development, SDG 3 is to '[e]nsure healthy lives and promote well-being for all at all ages', and one of its targets is to achieve UHC.

At both meetings it was clear that trillions, not billions, of dollars would be required to accomplish the SDGs. One estimate suggests incremental public and private spending needs in low- and lower-middle-income countries of 1.4 trillion (US\$ 2013) per year, of which \$68-\$87 billion (all public) is in the area of health (Schmidt-Traub, 2015). While mobilising these resources would be a huge step forward, it will at least not in the short term close all shortfalls from the target of $\$ 86$ in GHE per capita, which was one key target proposed by the Working Group. In 2012, these shortfalls amounted to a global financing gap of \$196 billion (Røttingen et al., 2014). Recent projections also suggest that even by 2040, only seven of today's low-income countries will have reached that target (Dieleman et al., 2016).

All this underscores the need for bold action on health financing. The need for action has recently also been demonstrated in the specific areas of domestic financing, financing of GPGHs and external financing.

\section{Domestic financing of health systems}

The Addis Ababa Action Agenda emphasises the centrality of domestic resource mobilisation in development financing and for achieving the SDGs. In particular, governments committed to fairer, more transparent and more efficient tax systems and to scale-up international tax cooperation, which is in line with the analyses presented in this supplement (McCoy et al., 2017). The 2030 Agenda for Sustainable Development also underscores that each country has primary responsibility for its own economic and social development. One of the targets highlighted in the 
Agenda is to strengthen domestic resource mobilisation, and the scope for doing this is thoroughly examined in this special issue (Elovainio \& Evans, 2017; Meheus and McIntyre, 2017). Concurrently, there has been a number of calls for better use of resources. In May 2014, the World Health Assembly affirmed the importance of national systems for health technology assessment with systematic use of evidence (World Health Organization [WHO], 2014), and the overarching theme of the 2016 Prince Mahidol Award Conference was 'priority setting for universal health coverage' (Prince Mahidol Award Conference, 2016).

\section{Joint financing of global public goods}

Two transnational health threats have come more prominently to the fore over the last two years. Ebola and later Zika have underscored the constant threat of emerging infectious diseases and the need for a much stronger system for preventing, detecting, and responding to epidemics (Moon et al., 2015; CHRF Commission, 2016; High-Level Panel on the Global Response to Health Crises, 2016). At the same time, the challenge of antimicrobial resistance has attracted more attention from policy makers, and, in May 2015, the World Health Assembly endorsed a global action plan to tackle resistance (World Health Organization (WHO), 2015a; Årdal et al., 2016). The Global Health Security Agenda, launched in February 2014, has also helped raising awareness about epidemics as well as antimicrobial resistance (Global Health Security Agenda, 2016).

Over the last two years, the World Health Assembly has also explored options to strengthen research and development for neglected diseases (WHO, 2014, 2015 b). Various pooled funds have been proposed for addressing GPGHs. One is a global biomedical R\&D fund for concurrently addressing emerging infectious diseases, antimicrobial resistance and neglected diseases (Balasegaram et al., 2015). Another is a fund for development of vaccines or biomedical countermeasures to epidemics more generally (Plotkin et al., 2015; CHRF Commission, 2016; High-Level Panel on the Global Response to Health Crises, 2016), and in 2016 the Coalition for Epidemic Preparedness Innovations (CEPI) was established to help finance and coordinate the development of new vaccines to prevent and contain infectious disease epidemics (CEPI, 2016). These and other systems to handle transnational health threats or ensure development of essential technologies need to be considered global goods (Moon et al., 2017).

Another, broad set of GPGHs comprise the factors helping create an enabling environment for health financing. The 2030 Agenda for Sustainable Development highlights tax collaboration, macroeconomic stability and equitable trade rules, and one target is to significantly reduce illicit financial flows (UN, 2015b). The recent Panama Papers have demonstrated how today's environment is far from an enabling one and underscored the importance of targeting financial secrecy (The International Consortium of Investigative Journalists, 2016). 


\section{External financing for national health systems}

While the spotlight is increasingly being put on domestic financing and global public goods, external financing will remain critical for many years ahead. Low-income countries in particular will be unable to achieve the SDGs through domestic means alone. One estimate indicates a gap of $\$ 152-\$ 163$ billion per year in these countries (Schmidt-Traub, 2015). This intensifies existing challenges in resource mobilisation as well as use. Both the Addis Ababa Action Agenda and the 2030 Agenda for Sustainable Development highlight the $0.7 \%$ official development assistance (ODA)/GNI target, but in 2015 only six countries reached this target (OECD, 2016a), and few additional countries are on track to reach this target anytime soon. While the Addis Ababa Action Agenda reaffirmed the European Union's commitment to achieve the target, this was done within the timeframe of 2030 (UN, 2015a).

With respect to the allocation of external funds, the Addis Ababa Action Agenda and the 2030 Agenda for Sustainable Development call for priority to the countries in greatest need and to the least developed countries (LDCs) (UN, 2015a, $2015 b)$. However, while total ODA increased in 2014, the amount going to LDCs fell (OECD, 2016b). To get a better understanding of country needs and the allocation of external financing for health, the Global Fund and eight other co-conveners recently ran the Equitable Access Initiative (Global Fund, 2016). This initiative demonstrated the impact of going beyond gross national product GNI per capita and considering countries' health needs and governments' fiscal capacity, and it recommended donors to take these factors into account when allocating funds. The need for a multi-dimensional set of allocation criteria has also recently been stressed by many others (Burgett et al., 2016), and is thoroughly discussed in this special issue (Moon \& Omole, 2017 and three papers by Ottersen et al. in this series).

The SDGs and other recent developments have also intensified questions about the allocation of funds across thematic areas. This is the case, for example, for priorities across the three health areas of the Millennium Development Goals (MDGs): maternal health, child health and the 'big three' infectious diseases (HIV/AIDS, malaria and tuberculosis). While the Global Fund has attracted funding towards the latter, the new Global Financing Facility (World Bank, 2015) may tilt the balance towards maternal and child health.

At the same time, the broader SDG agenda asks whether higher priority should be assigned to areas beyond the MDGs, including non-communicable diseases (NCDs). The SDGs also intensifies the question about the role of general health system strengthening and the pursuit of UHC in all this. Similarly, there is a question about to what extent, if any, external funds should be shifted towards GPGHs. Several donors have increased their attention to NCDs, health systems or both, and some donors have recently turned towards research for neglected diseases and antimicrobial resistance (HM Treasury, 2015). Moreover, Ebola has exposed the great need for 
support of national capacities to prevent, detect and respond to outbreaks (CHRF Commission, 2016). In this complex landscape, donors need to develop clear and well-founded criteria to guide the allocation of resources, and the criteria should be made publicly available to a greater extent than is the case today.

\section{Way forward}

The many recent developments underscore the Working Group's recommendations, the need to revise today's approach to domestic financing, the financing of GPGHs, and external financing, and the need to consider these areas holistically and seek a coherent global framework. Fortunately, the same developments offer valuable starting points for revision. Supplemented with clearer responsibilities and robust accountability mechanisms, the Addis Ababa Action Agenda and the 2030 Agenda for Sustainable Development can help facilitate a new global framework for health financing. The momentum of UHC draws attention towards the financing side of health systems and towards a systems perspective over a focus on single diseases. At the same time, Ebola and Zika may create a policy window where the neglected area of GPGHs can be better addressed. The Addis Ababa Action Agenda and the 2030 Agenda for Sustainable Development also highlight how the health sector can catalyse progress in other sectors and how external financing can catalyse domestic financing and the financing of GPGHs.

Overall, the need for a coherent global framework for health financing has become even clearer, and new stepping stones have emerged. These comes with opportunities not to be missed.

\section{Acknowledgements}

The authors are grateful to all members of the Working Group on Health Financing at Chatham House Centre on Global Health Security for their contributions to the final report discussed in this article and to Joseph Dieleman for his comments on an earlier draft of this article.

\section{References}

Årdal, C., K. Outterson, S. J. Hoffman, A. Ghafur, M. Sharland, N. Ranganathan, R. Smith, A. Zorzet, J. Cohn, D. Pittet, N. Daulaire, C. Morel, Z. Rizvi, M. Balasegaram, O. A. Dar, D. L. Heymann, A. H. Holmes, L. S. P. Moore, R. Laxminarayan, M. Mendelson and J.-A. Røttingen (2016), 'International cooperation to improve access to and sustain effectiveness of antimicrobials', Lancet, 387(10015): 296-307.

Balasegaram, M., C. Bréchot, J. Farrar, D. Heymann, N. Ganguly, M. Khor, Y. Lévy, P. Matsoso, R. Minghui, B. Pécoul, L. Peilong, M. Tanner and J.-A. Røttingen (2015), 'A global biomedical R\&D fund and mechanism for innovations of public health importance', PLoS Medicine, 12(5): e1001831. 
Burgett, A., S. Orzell and R. Salvado (2016), 'Running From Behind: Global Aid Allocation and the New Geography of Poverty', DPAF Working Paper Series, Seattle: Bill \& Melinda Gates Foundation.

Coalition for Epidemic Preparedness Innovations (2016), 'New vaccines for a safer world', CEPI, http://cepi.net/sites/default/files/CEPI_2_pager_23092016.pdf $[25$ September 2016].

CHRF Commission (2016), The Neglected Dimension of Global Security: A Framework to Counter Infectious Disease Crises, Washington, DC: National Academies Press.

Dieleman, J. L., T. Templin, N. Sadat, P. Reidy, A. Chapin, K. Foreman, A. Haakenstad, T. Evans, C. J. L. Murray and C. Kurowski (2016), 'National spending on health by source for 184 countries between 2013 and 2040', Lancet, 387(10037): 2521-2535.

Elovainio, R. and D. B. Evans (2017), 'Raising more domestic money for health: prospects for low and middle income countries', Health Economics, Policy and Law, 12(2): 139-157.

Global Fund (GF) (2016), 'Equitable access initiative', Global Fund to Fight AIDS, Tuberculosis and Malaria, http://www.theglobalfund.org/en/equitableaccessinitiative/ [25 September 2016].

Global Health Security Agenda (2016), Global Health Security Agenda, https:/ghsagenda.org/ [7 March 2016].

High-Level Panel on the Global Response to Health Crises (2016), 'Protecting Humanity From Future Health Crises', http://www.un.org/News/dh/infocus/HLP/2016-02-05_Final_ Report_Global_Response_to_Health_Crises.pdf [29 April 2016].

HM Treasury (2015), UK Aid: Tackling Global Challenges in the National Interest, London: HM Treasury.

The International Consortium of Investigative Journalists (2016), 'The Panama Papers', ICIJ, https://panamapapers.icij.org/ [17 June 2016].

Jamison, D. T., L. H. Summers, G. Alleyne, K. J. Arrow, S. Berkley, A. Binagwaho, F. Bustreo, D. Evans, R. G. A. Feachem, J. Frenk, G. Ghosh, S. J. Goldie, Y. Guo, S. Gupta, R. Horton, M. E. Kruk, A. Mahmoud, L. K. Mohohlo, M. Ncube, A. Pablos-Mendez, K. Srinath Reddy, H. Saxenian, A. Soucat, K. H. Ulltveit-Moe and G. Yamey (2013), 'Global health 2035: a world converging within a generation', Lancet, 382: 1898-1955.

McCoy, D., S. Chigudu and T. Tillmann (2017), 'Framing the tax and health nexus: a neglected aspect of public health concern', Health Economics, Policy and Law, 12(2): 179-194.

McIntyre, D., F. Meheus and J.-A. Røttingen (2017), 'What level of domestic government health expenditure should we aspire to for universal health coverage?', Health Economics, Policy and Law, 12(2): 125-137.

Meheus, F. and D. McIntyre (2017), 'Fiscal space for domestic funding of health and other social services', Health Economics, Policy and Law, 12(2): 159-177.

Moon, S. and O. Omole (2017), 'Development assistance for health: critiques, proposals and prospects for change', Health Economics, Policy and Law, 12(2): 207-221.

Moon, S., J.-A. Røttingen and J. Frenk (2017), 'Global public goods for health: weaknesses and opportunities in the global health system', Health Economics, Policy and Law, 12(2): 195-205.

Moon, S., D. Sridhar, M. A. Pate, A. K. Jha, C. Clinton, S. Delaunay, V. Edwin, M. Fallah, D. P. Fidler, L. Garrett, E. Goosby, L. O. Gostin, D. L. Heymann, K. Lee, G. M. Leung, J. S. Morrison, J. Saavedra, M. Tanner, J. A. Leigh, B. Hawkins, L. R. Woskie and P. Piot (2015), 'Will Ebola change the game? Ten essential reforms before the next pandemic. 
The report of the Harvard-LSHTM independent panel on the global response to ebola', Lancet, 386(10009): 2204-2221.

Organisation for Economic Co-operation and Development (2016a), 'Development aid rises again in 2015, spending on refugees doubles', OECD, http://www.oecd.org/newsroom/ development-aid-rises-again-in-2015-spending-on-refugees-doubles.htm [17 June 2016].

Organisation for Economic Co-operation and Development (2016b), 'Final Official Development Assistance Figures in 2014', OECD. http://www.oecd.org/dac/stats/final-oda-2014. htm [7 March 2016].

Plotkin, S. A., A. A. Mahmoud and J. Farrar (2015), 'Establishing a global vaccinedevelopment fund', The New England Journal Medicine, 373(4): 297-300.

Prince Mahidol Award Conference (2016), 'Priority setting', PMAC, http://pmaconference. mahidol.ac.th/index.php?option $=$ com_content $\&$ view $=$ article $\& i d=743 \&$ Itemid $=213$ [6 March 2016].

Røttingen, J.-A., T. Ottersen, A. Ablo, D. Arhin-Tenkorang, C. Benn, R. Elovainio, D. B. Evans, L. E. Fonseca, J. Frenk, D. McCoy, D. McIntyre, S. Moon, G. Ooms, T. Palu, S. Rao, D. Sridhar, J. Vega, S. Wibulpolprasert, S. Wright and B. M. Yang (2014), Shared Responsibilities for Health: A Coherent Global Framework for Health Financing, London: Chatham House.

Schmidt-Traub, G. (2015), 'Investment needs to achieve the Sustainable Development Goals: understanding the billions and trillions', SDSN Working Paper, Version 2, Paris and New York: Sustainable Development Solutions Network.

United Nations (UN) (2015a), Addis Ababa Action Agenda of the Third International Conference on Financing for Development, New York: UN.

United Nations (UN) (2015b), 'Transforming our world: the 2030 agenda for sustainable development', resolution adopted by the General Assembly on 25 September 2015, UN, New York.

World Bank (2015), 'Global financing facility in support of every woman every child', http:// www.worldbank.org/en/topic/health/brief/global-financing-facility-in-support-of-everywoman-every-child [7 March 2016].

World Health Organization (WHO) (2014), Sixty-Seventh World Health Assembly. Resolutions and Decisions, Geneva: WHO.

World Health Organization (WHO) (2015a), 'Global action plan on antimicrobial resistance', Sixty-Eighth World Health Assembly, Agenda item 15.1, WHO, Geneva.

World Health Organization (WHO) (2015b), 'Follow-up of the report of the consultative expert working group on research and development: financing and coordination', sixty-eight world health assembly, provisional agenda item 17.4, WHO, Geneva. 